\title{
Assessment of nasal patency after rhinoplasty through the Glatzel mirror
}

\author{
Victor Diniz de Pochat', Nivaldo Alonso², Rogério Rafael da Silva Mendes ${ }^{3}$, Paula Rocha Gravina ${ }^{4}$ Eduardo Valente Cronenberg ${ }^{5}$, \\ José Valber Lima Meneses ${ }^{6}$.
}

1) $\mathrm{MD}, \mathrm{PhD}$. Substitute Associate Professor of Plastic Surgery in the Federal University of Bahia - Medical School.

2) MD, Full Professor. Chief of Craniofacial Surgery Department in the Clinical Hospital - USP. Division of Plastic Surgery - HC-FMUSP, São Paulo/SP.

3) MD. Past President of LBCP. Medical School of Federal University of Bahia, Salvador/BA.

4) Medical Student. President of LBCP. Federal University of Bahia. Salvador/BA

5) Medical Student. Federal University of Bahia. Salvador/BA.

6) MD, PhD. Associate Professor. Chief of the Plastic Surgery in the HUPES. Division of Plastic Surgery, Department of Surgery. HUPES - UFBA, Salvador/BA.

Institution: Divisão de Cirurgia Plástica. Departamento de Cirurgia - Faculdade de Medicina da Universidade Federal da Bahia. Pavilhão de aulas da Faculdade de Medicina - Av. Reitor Miguel Calmon, s/n, Vale do Canela - CEP 40110-100. Salvador / BA - Brazil.

Mailing address: Victor Diniz de Pochat - Rua Conselheiro Corrêa de Menezes, 432 - Apto. 201 - Horto Florestal - Salvador / BA - Brazil - E-mail: victor.pochat@ gmail.com Article received in November 29, 2011. Article approved in February 6, 2012.

\section{SUMMARY}

Introduction: Objective evaluation of nasal function is a constant challenge for plastic surgeons, otolaryngologists, and allergists. The modified Glatzel mirror can evaluate nasal expiratory flow; however, there is little information on this method and its use in the measurement of nasal patency after surgical procedures.

Objective: To compare, in a prospective study, the functional results before and after cosmetic rhinoplasty and evaluate the use of the Glatzel mirror as an objective method to assess nasal patency.

Methods: To achieve this objective, we analyzed the functional results of surgery through a subjective questionnaire and objective evaluation through a modified Glatzel mirror, and evaluated the correlation between the 2 methods. Twenty patients (14 women and 6 men) underwent aesthetic rhinoplasty using spreader grafts. Pre- and postoperative evaluation (90-120 days) included a respiratory quality score (subjective) and modified Glatzel mirror test (objective). Subsequently, the Spearman test was used to compare the pre- and postoperative subjective and objective data.

Results: The subjective evaluation demonstrated a statistical difference between pre- and postoperative scores ( $8 \pm 2$ and 9.4 $\pm 0.7, \mathrm{P} \leq 0.001)$. There was no statistical difference in mean nasal patency by modified Glatzel mirror. No statistically significant correlation was observed when comparing the modified Glatzel mirror values with the subjective scores reported by patients pre- or postoperatively.

Conclusion: The Glatzel method lacks sensitivity in detecting patient-reported improvements in breathing following rhinoplasty. This suggests that the method is a poor assessment tool to detect small, post-surgical changes in the nasal airways.

Keywords: evaluation, rhinoplasty, respiration.

\section{INTRODUCTION}

To measure nasal function objectively is a constant challenge for plastic surgeons, otolaryngologists, speech pathologists, physiologists, and allergists $(1,2)$. The patient's perception is important, but does not define the degree of obstruction or the degree of improvement after a certain treatment. Among the methods currently available for evaluation of respiratory function, the most common are computed rhinomanometry and acoustic rhinometry (3). Breathing can also be measured by using the nasal Glatzel mirror or the Altmann graph mirror, widely used by speech therapists in the evaluation of nasal airflow $(4,5)$. The modified Glatzel mirror (Altmann graph mirror) enables evaluation of the nasal expiratory flow, and is used to analyze changes in nasal ventilation in patients undergoing certain therapies or changing habits (4-6). The use of spreader grafts as "spacers" between the dorsal cartilaginous septum and upper lateral cartilage is a well-established method for the correction or prevention of internal nasal valve failure during rhinoplasty $(7,8)$; however, there is little information in the literature about the modified Glatzel mirror and its use in the objective measurement of nasal patency after surgical procedures.

The objective of this study was to compare the functional results before and after cosmetic rhinoplasty and evaluate the use of the modified Glatzel mirror as an objective method to assess nasal patency. To this end, we analyzed the functional results of surgery through a subjective questionnaire and with the modified Glatzel mirror, and evaluated the correlation between the 2 methods. 


\section{MetHOD}

\section{Subjects}

This prospective clinical study was approved by the Ethics and Research Committees of the University of São Pauloand the Federal University of Bahia, and was conducted between September 2009 and December 2010. The sample consisted of 20 consecutive healthy patients (14 women and 6 men) who were scheduled to undergo cosmetic rhinoplasty (with or without associated functional complaints). Patients with racial and ethnic characteristics (blacks and Asians) and history of nasal trauma, nasal surgery, smoking, and medical co-morbidities (cancer, hypertension, diabetes mellitus, and renal, pulmonary, cardiac, or hepatic conditions) were excluded.

\section{Evaluation}

All patients underwent a pre- and postoperative (90-120 days after the procedure) evaluation. The subjective evaluation was conducted through a questionnaire in which each patient scored their breathing quality with a respiratory score of 1 (poor) to 10 (excellent). The patients were not told their previous score at the time of the postoperative evaluation to avoid influencing the results. Nasal patency was assessed objectively through the modified Glatzel mirror by a single examiner (first author). Expiratory flow was measured by marking the halo (condensate flow) on the mirror projector with a pen. This mirror consisted of a metal plate, marked in millimeters, with a flat side and another side with a recessed groove for the nose. Patients sat with their heads positioned vertically, and first performed forced expirations through each nostril, and then they were asked to exhale normally with the mouth closed. The halo of condensation obtained after normal expiration was marked with a ballpoint pen and then transferred to a reference card marked in millimeters.

Irregular markings on the mirror caused by nasal aeration were quantified in square centimeters $\left(\mathrm{cm}^{2}\right)$ (Figure 1), recorded separately for the left and right side, and analyzed with UTHSCSA Image Tool for Windows version 3.0 (San Antonio, TX, USA) (9). To account for variability in ambient conditions, measurements of temperature and humidity were obtained for all patients at the time of examination. The temperature range was 25$27.8{ }^{\circ} \mathrm{C}$, and humidity was $57-67 \%$.

\section{Surgical technique}

All patients were operated on under general anesthesia and local anesthesia with lidocaine infiltration

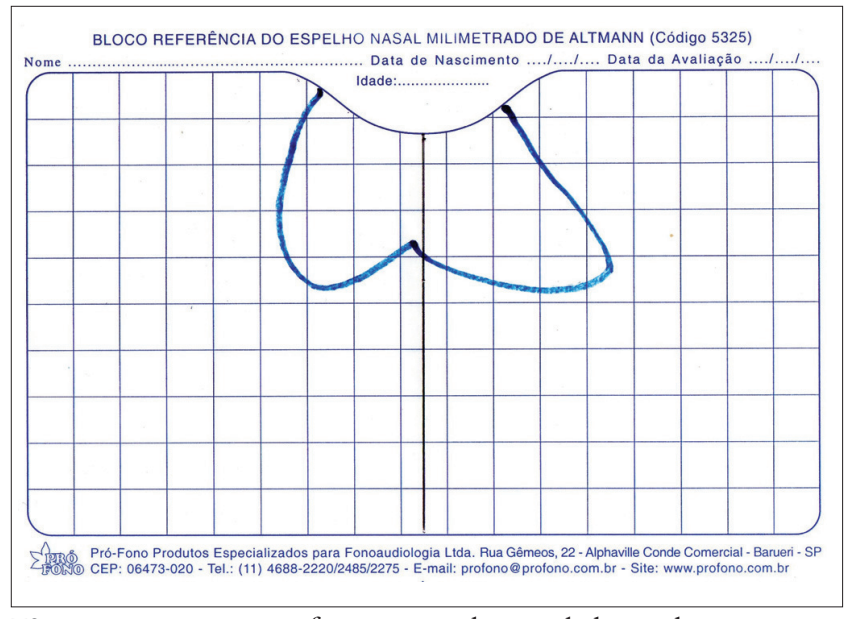

Figure 1. Geometric formation obtained through expiration (blue); vertical line (black) created to separate left and right sides.

(0.5\%) and epinephrine (1:80,000), and a single surgeon (first author) performed all surgeries. The technique employed was similar in all cases, using the open rhinoplasty approach and spreader grafts between the upper lateral cartilage and the septum. Aesthetic deformities were treated according to the individual needs of each patient. Osteotomies were performed in 16 patients (80\%).

\section{Data analysis}

Nonparametric tests were used for statistical analysis. The Kolmogorov-Smirnov test was used to assess whether the data assumed normal distribution. After verifying that conditions of normality were not met, the Wilcoxon test was used. The Spearman correlation test was used to compare the pre- and postoperative subjective and objective data. Statistical analysis was performed using SPSS version 13.0, and graphs and tables were created in Microsoft Excel and Word 2007. A significance level of $<0.05$ was set for all analysis.

\section{RESULTS}

Patient follow-up ranged 5-15 months. Analysis of the subjective sensation of nasal patency revealed statistical significance (Table 1). While the subjective sensation of patency was improved in $70 \%$ of patients, there was no change in the quality of breathing in the remaining 30\%. There was no statistical difference between pre- and postoperative or left and right mean nasal patency by the modified Glatzel mirror (Table 2). No statistically significant correlation was observed when comparing modified Glatzel mirror values with patient-reported scores during the subjective evaluation, either in pre- or postoperative assessments (Table 3). 
Table I. Descriptive analysis of the subjective sensation of nasal patency before and after surgery

\begin{tabular}{lccc}
\hline & $\mathrm{n}$ & Mean & $\mathrm{SD}$ \\
\hline Pre & 20 & 7.9 & 1.61 \\
Post & 20 & 9.35 & 0.74
\end{tabular}

Note: Nonparametric Wilcoxon test, $\mathrm{p}$ (pre $\mathrm{x}$ post) $=0.001$, statistically significant.

$\mathrm{n}=$ absolute number, $\mathrm{SD}=$ standard deviation .

Table 2. Mean \pm standard deviation of the modified Glatzel mirror according to side and time.

\begin{tabular}{lccc}
\hline & Pre $\left(\mathrm{cm}^{2}\right)$ & Post $\left(\mathrm{cm}^{2}\right)$ & p-value \\
\hline Left & $12.9 \pm 5.15$ & $14.55 \pm 6.03$ & $\mathrm{~ns}$ \\
Right & $12.16 \pm 4.94$ & $12.9 \pm 5.07$ & $\mathrm{~ns}$ \\
p-value & $\mathrm{ns}$ & $\mathrm{ns}$ &
\end{tabular}

Note: Nonparametric Wilcoxon test, statistically significant pvalue $\leq 0.05$

Pre $=$ preoperative, Post $=$ postoperative .

Table 3. Coefficients of Spearman linear correlation between the parameters: pre-and postoperative subjective analysis and modified Glatzel mirror values.

\begin{tabular}{lcc}
\hline & Glatzel Left & GlatzelRight \\
\hline SubjectivePre & 0.247 & 0.027 \\
SubjectivePost & -0.027 & 0.04
\end{tabular}

* Correlation significant to 0.01 .

Subjective analysis before x Glatzel mirror (right and left) before, no significant correlation.

Subjective analysis after x Glatzel mirror (right and left) after, no significant correlation.

\section{DISCUSSION}

The ideal rhinoplasty includes preservation or improvement of respiratory function. The data from this study revealed significant improvement in subjective breathing after open rhinoplasty with the use of spreader grafts. Several methods have been developed to assess nasal flow patency objectively. The clinical benefit of objective airway assessment is clear, as it permits better diagnosis, treatment monitoring, and scientific and legal documentation (10). The modified Glatzel mirror method is often used in clinical practice and has the advantage of being reproducible, rapid, non-invasive, inexpensive, and does not require special training.

Degan and Puppin Rontani (4) demonstrated increased nasal aeration after orofacial myofunctional therapy, comparing the condensation area on the mirror before and after treatment. Meso et al. (11) reported an increase in nasal aeration after massage and nasal cleansing; however, BAssi et al. (6) suggested that the use of the mirror as a nasal patency assessment method should be restricted to surgical patients and those with allergies.

In the present study, there was no statistical significance between pre-and postoperative measurements using the modified Glatzel method. Despite being easy to perform, the degree of reliability and reproducibility in the evaluation of nasal airflow when using this method has not been well established, and medical reports referring to it in the literature differ (12-15). Other studies have suggested that there are factors related to the sensation of nasal patency not necessarily linked to the flow of air $(15,16)$. Factors such as examiner technique, instrument characteristics, and changes in shape and size of the airway (nose) can interfere with results (17). With regard to examiner technique, the same examiner (first author) was responsible for all measurements, taking into account manufacturer recommendations and standardizing protocols to reduce the variability of the results. As for limitations of the instrument (mirror), it is unable to regulate the flow of condensation, which results in measurement error in seconds. Increasing the number of measurements to 3 or 5 could reduce this bias. Variation in study subjects and anatomic differences in the nasal airway among them are beyond the investigator's control. Another explanation for the variability of the results may be related to the nasal cycle. The nasal cycle may be defined as a periodic alternation of congestion and secretion from the nasal cavity, which changes the feeling of nasal patency and nasal resistance to the flow of air (18). While one nostril is congested, reducing its seromucous gland secretion, the other unblocks and increases its glandular secretion. This mechanism is regulated by a balance alternating between sympathetic and parasympathetic systems and by different chemical mediators. The nasal cycle can be observed in most individuals without respiratory disease, lasting from as short as 30 minutes to more than 7 hours. This cycle is influenced by several factors, including environmental conditions, body position, age, presence of nasal disorders, and emotional and hormonal stimuli.

The examinations were performed in the same physical space by the same examiner under similar temperature and humidity conditions. Despite the routine employed, it was not possible to control emotional and hormonal stimuli, or even quantify the duration of the nasal cycle of each patient. In the medical literature, there is no description of values considered normal for the area of condensation on the modified Glatzel mirror. Moreover, most studies only included children, making it difficult to compare previously published results with that of the present study. The correlation between nasal airflow and 
subjective sensation of nasal patency has been studied extensively with several methods, leading to divergent results. WATSON et al. (12) suggested that children are insensitive to subjective assessment of nasal patency, while Fisher et al. (19) demonstrated that the nasal cycle pattern of children is similar to that of adults. On the other hand, other authors have demonstrated a poor correlation between the sensation of nasal obstruction and nasal resistance in adults, both by objective measurement and rhinometry (13). FAIRLEY etal. (20) obtained good correlation between subjective and objective assessments. This study involved only 5 subjects with multiple measurements; thus, we obtained a linear regression curve for each subject, allowing individual examination. The general assessment of all subjects would lead to an incorrectly low correlation, as each individual has his own calibration curve. Studies conducted with individuals who have physiologically increased nasal resistance have also demonstrated significant correlation $(21,22)$.

\section{CONCLUSION}

The Glatzel method lacks sensitivity in detecting patient-reported improvements in breathing following rhinoplasty. This suggests that the method is a poor assessment tool to detect small, post-surgical changes in the nasal airway.

\section{REFERENCES}

1. Passos AP, Alonso N, Utsunomia K, Ferreira MC. The accuracy of rhinometry in the evaluation of the nasal valve: study in 385 patients. Rev Bras Cir Plást, 2009; 24:262-4.

2. Pochat V, Alonso N, Meneses J. Avaliação funcional e estética da rinoplastia com enxertos cartilaginosos. Rev Bras Cir Plást, 2010; 25:260-70.

3. Zancanella E, Lima W'TA. Acoustic rhinometry as a diagnostic method. Rev Bras Otorrinolaringol, 2004; 70:500-3.

4. Degan VV, Puppin-Rontani RM. Aumento da aeração nasal após remoção de hábitos de sucção e terapia miofuncional. Revista CEFAC, 2007; 9:55-60.

\section{Altmann EBC. Espelho nasal milimetrado.}

6. Bassi IB, Franco LP, Motta AR. Eficácia do emprego do espelho de Glatzel na avaliação da permeabilidade nasal. Revista da Sociedade Brasileira de Fonoaudiologia, 2009; 14:367-71.

7. Sheen JH. Spreader graft: a method of reconstructing the roof of the middle nasal vault following rhinoplasty. Plast Reconstr Surg, 1984; 73:230-9.

8. Howard BK, Rohrich RJ. Understanding the nasal airway: principles and practice. Plast Reconstr Surg, 2002; 109:112846; quiz 45-6.

9. Wilcox D, Dove B, McDavid D, Greer D. UTHSCSA Image Toll for Windows. 3.00 ed. Texas: The University of Texas Health Science Center; 2002.

10. Cole P, Roithmann R, Roth Y, Chapnik JS. Measurement of airway patency. A manual for users of the Toronto systems and others interested in nasal patency measurement. Ann Otol Rhinol Laryngol Suppl, 1997; 171:1-23.

11. Melo FMGd, Cunha DAd, Silva HJd. Avaliação da aeração nasal pré e pós a realização de manobras de massagem e limpeza nasal. Rev CEFAC, 2007; 9:375-82.

12. Watson WT, Roberts JR, Becker AB, Gendreau-Reid LF, Simons FE. Nasal patency in children with allergic rhinitis: correlation of objective and subjective assessments. Ann Allergy Asthma Immunol; 1995; 74:237-40.

13. Hardcastle PF, White A, Prescott RJ. Clinical and rhinometric assessment of the nasal airway-do they measure the same entity? Clin Otolaryngol Allied Sci, 1988; 13:185-91.

14. Eccles RB. The nasal cycle in respiratory defence. Acta Otorhinolaryngol Belg, 2000; 54:281-6.

15. Burrow A, Eccles R, Jones AS. The effects of camphor, eucalyptus and menthol vapour on nasal resistance to airflow and nasal sensation. Acta Otolaryngol, 1983; 96:157-61.

16. Jones AS, Crosher R, Wight RG, Lancer JM, Beckingham E. The effect of local anaesthesia of the nasal vestibule on nasal sensation of airflow and nasal resistance. Clin Otolaryngol Allied Sci, 1987; 12:461-4.

17. Brescovici S, Roithmann R. A reprodutibilidade do espelho de Glatzel modificado na aferição da permeabilidade nasal. Rev Bras Otorrinolaringol, 2008; 74(2):215-222.

18. Hasegawa M. Nasal cycle and postural variations in nasal resistance. Ann Otol Rhinol Laryngol, 1982; 91:112-4.

19. Fisher EW, Palmer CR, Lund VJ. Monitoring fluctuations in nasal patency in children: acoustic rhinometry versus rhinohygrometry. J Laryngol Otol, 1995; 109:503-8.

20. Fairley JW, Durham LH, Ell SR. Correlation of subjective 
sensation of nasal patency with nasal inspiratory peak flow rate. Clin Otolaryngol Allied Sci, 1993; 18:19-22.

21. Sipila J, Suonpaa J, Laippala P. Sensation of nasal obstruction compared to rhinomanometric results in patients referred for septoplasty. Rhinology, 1994; 32:141-4.
22. Simola M, Malmberg H. Sensation of nasal airflow compared with nasal airway resistance in patients with rhinitis. Clin Otolaryngol Allied Sci, 1997; 22:260-2. 